T. Patiño, J. Soriano, E. Amirthalingam, S. Durán, A. González-Campo, M. Duch, E. Ibáñez, L. Barrios, J. A. Plaza, L. Pérez-García and C. Nogués "Polysilicon-chromium-gold intracellular chips for multifunctional biomedical applications”, Nanoscale, 8, 8773-8783, 2016,

DOI: $10.1039 / C 5 N R 09022 A$

http://pubs.rsc.org/en/content/articlelanding/2016/nr/c5nr09022a\#!divAbstract 


\section{Polysilicon-chromium-gold intracellular chips for multi-functional biomedical applications}

Tania Patiño, Jorge Soriano, ${ }^{a}$ Ezhil Amirthalingam, ${ }^{\mathrm{b}}$ Sara Durán, Arántzazu González-Campo, Marta Duch, ${ }^{\mathrm{c}}$ Elena Ibáñez, ${ }^{\mathrm{a}}$ Leonardo Barrios, ${ }^{\mathrm{a}}$ Jose Antonio Plaza, ${ }^{\mathrm{c}}$ Lluïsa Pérez-García $\dagger^{\mathrm{b}}$ and Carme Nogués*a

The development of micro- and nanosystems for their use in biomedicine is a continuously growing field. One of the major goals of such platforms is to combine multiple functions in a single entity. However, achieving the design of an efficient and safe micro- or nanoplatform has shown to be strongly influenced by its interaction with the biological systems, where particle features or cell types play a critical role. In this work, the feasibility of using multi-material pSi-Cr-Au intracellular chips (MMICCs) for multifunctional applications by characterizing their interactions with two different cell lines, one tumorigenic and one non-tumorigenic, in terms of biocompatibility, internalization and intracellular fate, has been explored. Moreover, the impact of MMICCs on the induction of an inflammatory response has been assessed by evaluating TNF $\alpha$, IL1b, IL6, and IL10 human inflammatory cytokines secretion by macrophages. Results show that MMICCs are biocompatible and their internalization efficiency is strongly dependent on the cell type. Finally as a proof-of-concept, MMICCs have been dually functionalized with transferrin and $\mathrm{pHrodo}^{\mathrm{TM}} \mathrm{Red}$, SE to target cancer cells and detect intracellular $\mathrm{pH}$, respectively. In conclusion, MMICCs can be used as multi-functional devices due to their high biocompatibility, non-inflammatory properties and the ability of developing multiple functions.

Introduction

The fast development of micro- and nanotechnologies in recent years has opened new and promising avenues to overcome some of the limitations of classical diagnostics and therapeutic medical approaches. $1^{-}$ ${ }^{3}$ Fabrication of micro- and nanoplatforms for biomedical applications can be achieved by either "bottomup" or "top-down" synthetic strategies. ${ }^{4}$ In "bottom-up" approaches, drug delivery tools are assembled from the molecular scale, by manipulating their chemical and physical properties, whereas "top-down" approaches are based on the adaptation of semiconductor industry microfabrication techniques such as lithography. ${ }^{5}$ 
Despite having received less attention in the biomedical field, the use of "top-down" based microfabrication techniques for the development of microelectromechanical systems (MEMS) has shown a great potential for several applications such as drug delivery, ${ }^{6-9}$ controlled-release $^{10-12}$ and diagnostics. ${ }^{13}$ Moreover, the miniaturization of biological microelectromechanical system (BioMEMS) through combining microfabrication and nanotechnology techniques has allowed the creation of small silicon-based chips, which may be internalized by cells $\mathrm{s}^{14,15}$ and are able to detect intracellular parameters such as esterase activity ${ }^{16}$ or pressure. ${ }^{17}$ In this regard, "top-down" microfabrication techniques offer some advantages over "bottom-up" approaches, such as a highly precise control upon the size, shape and monodispersity of the particles. ${ }^{1}$ This is of special relevance, as particle shape and size have been proven to play a key role in the interaction of microand nanodevices with biological systems. ${ }^{18-23}$ One step forward in the biomedical application of such devices would consist of combining diagnostic and therapeutic functions, since this is a main challenge for nanomedicine. ${ }^{24-26}$ In this regard, we have recently demonstrated that the use of multimaterial devices is an interesting approach for multifunctional purposes, as the different layers can be functionalized by using orthogonal chemistry. ${ }^{27}$

On the other hand, despite the encouraging outcomes from the use of micro- and nanoengineered platforms for intracellular applications, a deeper understanding of particle-cell interactions has become increasingly important in order to develop efficient and safe micro- and nanoplatforms. ${ }^{28}$ In this sense, it has been shown that several features of particle design, such as size,19,20,29-31 shape22,32 and surface properties,33-35 play a critical role in several biological parameters, such as uptake efficiency, internalization or cytotoxicity. In addition, the biological responses to a specific type of particle are closely related to the cell type, as different cell types have shown to respond differently to a certain particle feature. ${ }^{36-38}$

In the present work, we aimed to investigate the feasibility of multi-material silicon chips for their use as multi-functional intracellular devices. With this purpose, we first characterized the biological interactions between multi-material polysiliconCr-Au intracellular chips (MMICCs) and two human breast epithelial cell types, the adenocarcinoma derived SKBR-3 and non-tumorigenic MCF-10A cells, in terms of biocompatibility, uptake and intracellular location. Second, we evaluated whether MMICCs induced an inflammatory response in THP-1 cell-derived macrophages. Finally, we used orthogonal wet chemistry to differently functionalize the gold and polysilicon layers, taking advantage of the multi-material nature of the chips, in order to render the MMICCs multifunctional. On the one hand, we functionalized the polysilicon layer with transferrin (Tf), fluorescein conjugated (Tf-FITC), in order to target the tumorderived SKBR-3 cells, as the transferrin receptor has shown to be overexpressed in most types of cancer 
cells. ${ }^{39-41}$ On the other hand, we functionalized the Au layer with pHrodo ${ }^{\mathrm{TM}} \mathrm{Red}$, SE in order to detect intracellular $\mathrm{pH}$.

\section{Results}

Characterization of MMICCs 
a)

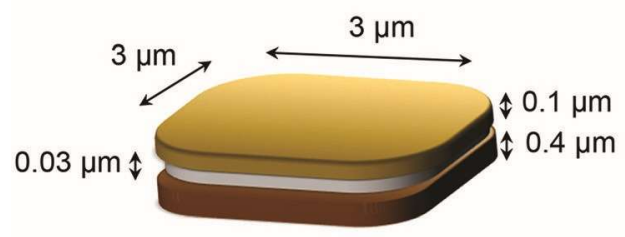

$\triangle \mathrm{Au} \quad \mathrm{Cr} \quad \square$ pSi

c)

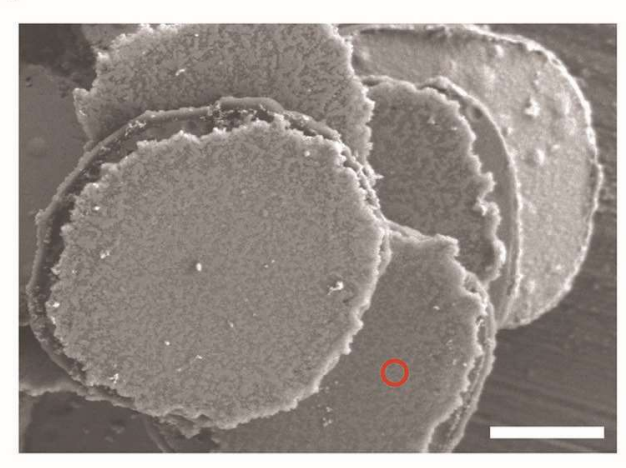

b)

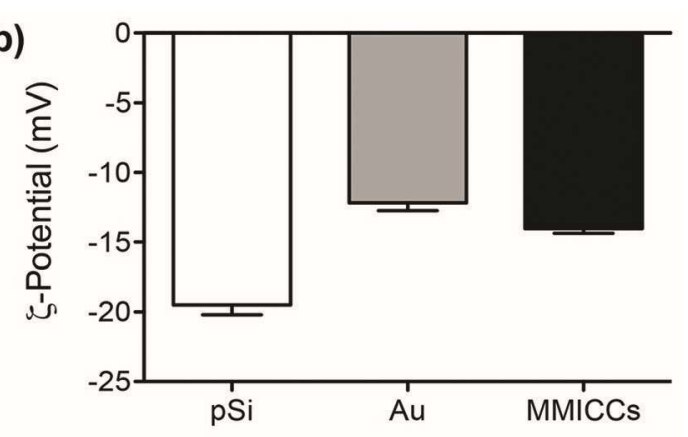

d)

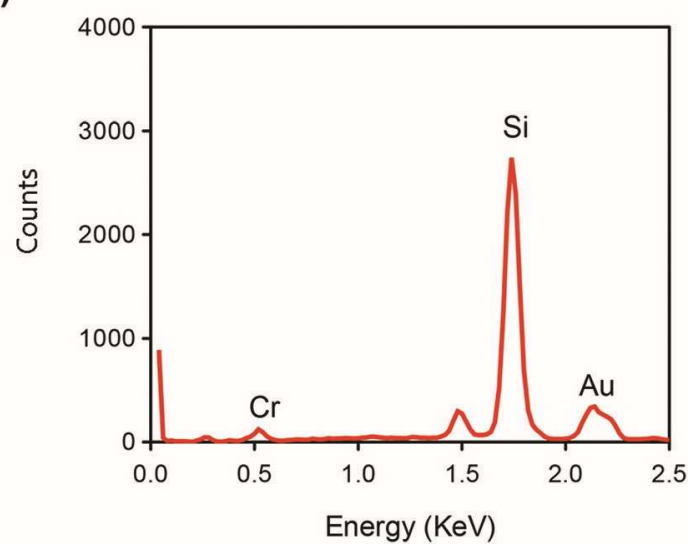


Fig. 1 Design and characterization of MMICCs. (a) Schematic representation of the design of MMICCs, where the dimensions and thickness of the different material layers are specified. (b) $\zeta$-Potential of MMICCs and single-material polysilicon and Au chips. Results are shown as the Mean \pm SEM. (c) SEM image of MMICCs, where the actual size and material composition can be observed. Red circle indicates the area where the EDX analysis was performed. Scale bar $=1 \mu \mathrm{m}$. (d) EDX spectrum confirming the presence of $\mathrm{Si}, \mathrm{Au}$ and $\mathrm{Cr}$.

Fig. 1a shows the MMICCs design. MMICCs have a square shape of $3 \mu \mathrm{m} \times 3 \mu \mathrm{m}$ in length and width and $0.5 \mu \mathrm{m}$ of thickness $(0.1 \mu \mathrm{m}, 0.03 \mu \mathrm{m}$ and $0.4 \mu \mathrm{m}$ for the gold, chromium and polysilicon layers, respectively). The $\zeta$-potential measurements showed that both single-material polysilicon and gold chips were negatively charged, with more negative surface charges in the case of polysilicon. MMICCs showed intermediate values of negative surface charges with respect to their gold and polysilicon counterparts (Fig. 1b). The SEM images showed that MMICCs were successfully fabricated, as the three different layers were observed (Fig. 1c). The different layers could be easily distinguished by the variation of surface roughness, the 
gold layer being rougher than the polysilicon one. The intermediate $\mathrm{Cr}$ layer was not visible under SEM due to its internal location as well as its extremely low thickness. However, EDX analyses demonstrated that the three materials, $\mathrm{Si}, \mathrm{Au}$ and $\mathrm{Cr}$, were present in the MMICCs, since the corresponding peaks for these elements were observed (Fig. 1d).

Uptake of MMICCs by SKBR-3 and MCF-10A cells 

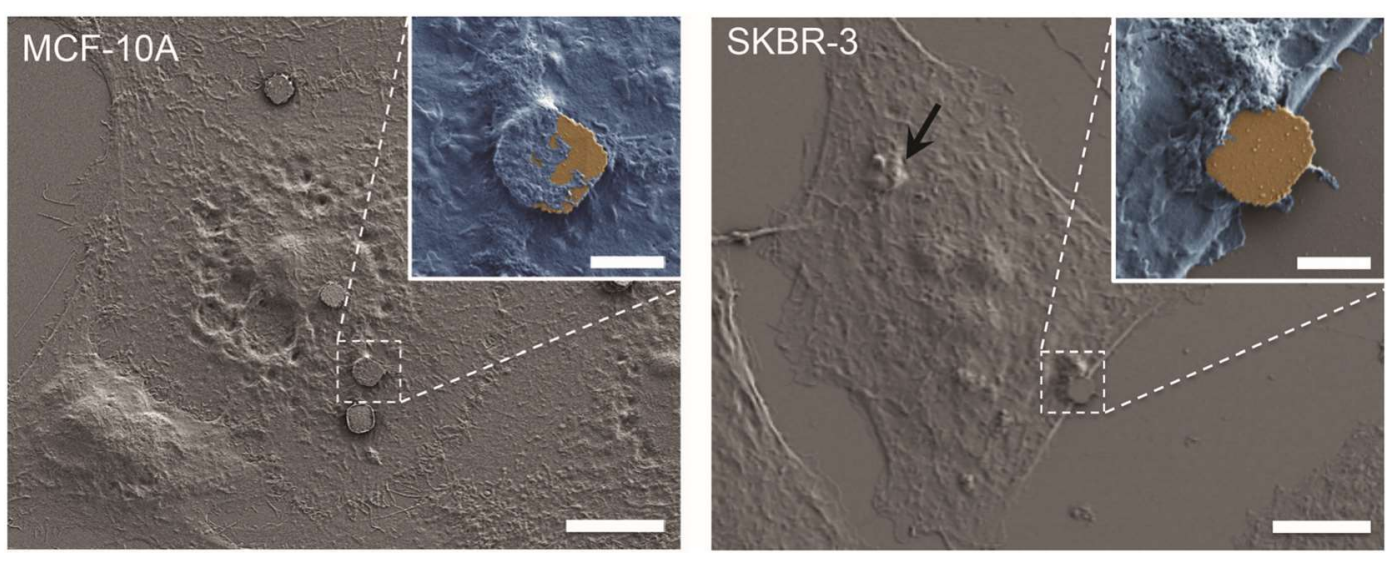

Fig. 2 Evaluation of MMICCs internalization by SEM. Images show that MMICCs were actively taken up by cells, as the plasma membrane was observed in the process of surrounding MMICCs in both cell lines. Arrow points completely internalized MMICCs. Scale bar $=10 \mu \mathrm{m}$. Insets show a magnification of the selected area, artificially colored for a better visualization of the plasma membrane. Scale bar $=2 \mu \mathrm{m}$. 

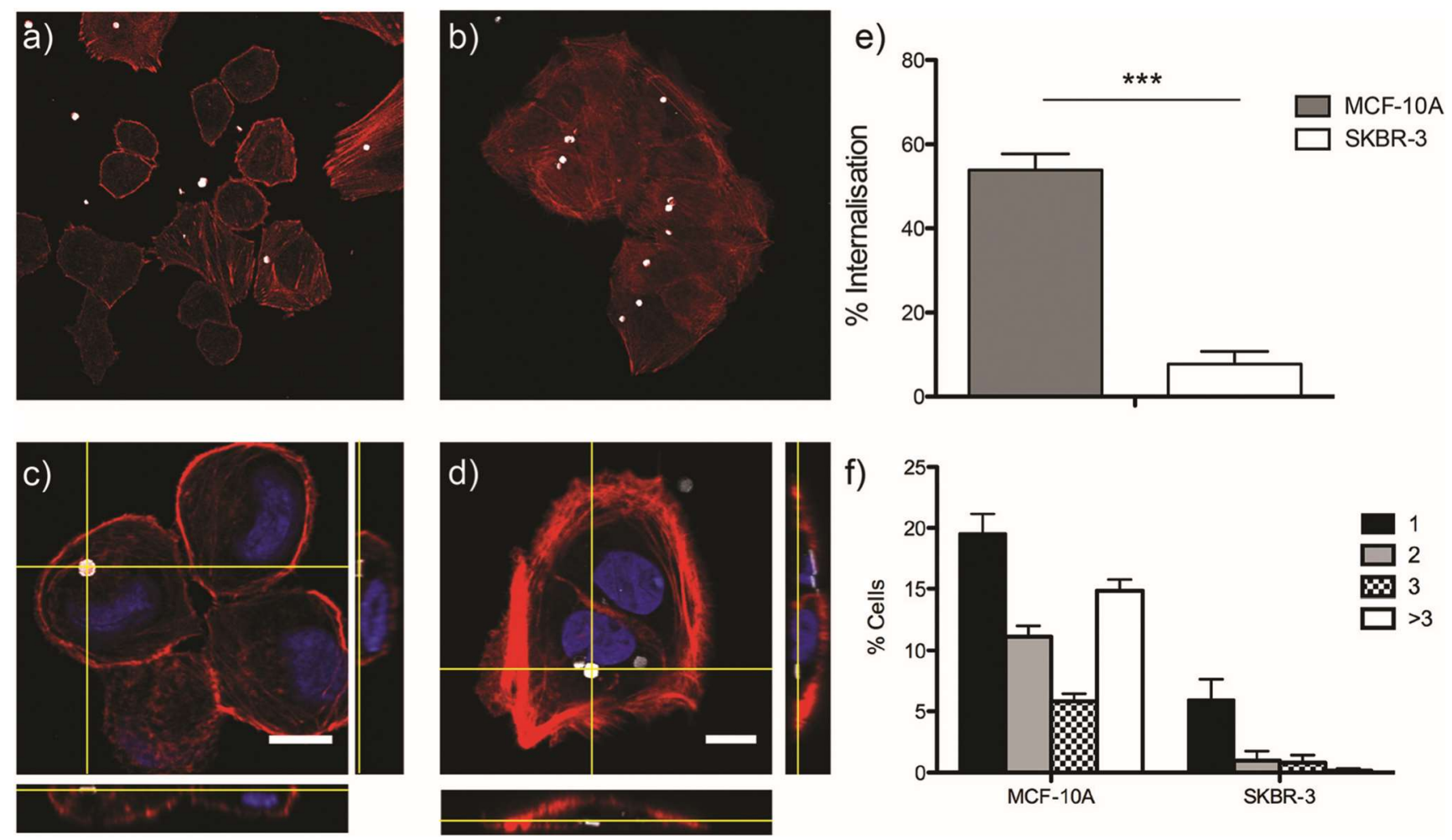

Fig. 3 Quantitative analysis of MMICC uptake by CLSM. (a-d) Images show SKBR-3 and MCF-10A cells, respectively, after $24 \mathrm{~h}$ incubation with MMICCs. Actin filaments were stained with Texas red® phalloidin (red) and cell nuclei were stained with Hoechst 33258 (blue). MMICCs were imaged by using the reflection mode. Scale bar $=10 \mu \mathrm{m}$. (c,d) Orthogonal views of reconstructed Z-stacks of SKBR-3 (c) and MCF-10A (d) cells. Scale bar $=10 \mu \mathrm{m}$. (e) percentage of cells that had internalized at least one MMICC. (f) Distribution of cell populations according to the number of particles internalized per cell. Results are shown as the mean \pm SEM. Asterisks $(* * *)$ indicate significant differences between both cell lines $(\mathrm{p}=0.001)$. A qualitative assessment of MMICC uptake was carried out by SEM imaging, after 4 and $24 \mathrm{~h}$ of coincubation. Both in SKBR-3 and MCF-10A lines, cells showed an active uptake of MMICCs, as a membrane evagination surrounding MMICCs 
was observed (Fig. 2). In addition, in some cases, a cell protrusion was observed, indicating that chips were completely internalized (Fig. 2, arrow). In order to further confirm that the chips had been completely internalized and to quantify MMICC uptake, CLSM imaging was also performed (Fig. 3). Confocal analysis showed that the number of MMICCs associated with cells was higher in MCF-10A than in SKBR-3 cells (Fig. 3a-b). In order to determine whether MMICCs had been internalized by cells, orthogonal projections of Z-stack reconstruction of consecutive focal planes $(0.4 \mu \mathrm{m}$ each) were analyzed (Fig. 3c-d). Two hundred cells were analyzed for each cell line in three independent experiments. Results showed that the MMICC internalization efficiency was significantly $(\mathrm{P}<$

0.001) higher in MCF-10A cells than in SKBR-3 cells (Fig. 3e).

Moreover, confocal imaging allowed to precisely determine the number of particles internalized per cell, in both cell lines (Fig. 3f). In this regard, it was shown that the majority of MCF-10A cells internalized more than one MMICC, whereas in the case of SKBR-3 the majority of cells internalized only one MMICC.

\section{Cytotoxicity of MMICCs}

The percentage of viable cells in three independent experiments was assessed at both 24 and $72 \mathrm{~h}$ after incubation with the MMICCs (Fig. 4). Results showed that MMICCs did not affect cell viability, as a high percentage of viable cells $(>80 \%)$ was observed in both cell lines at both time points. Moreover, no significant differences were observed between cell lines,

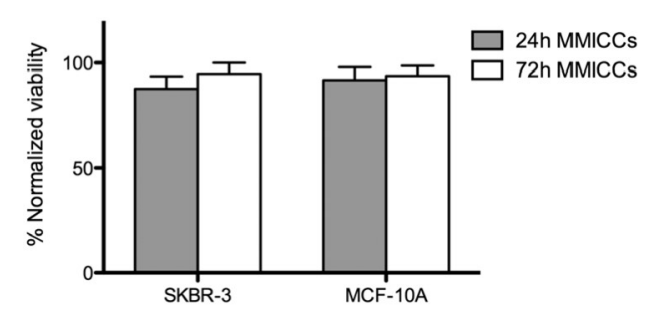

Fig. 4 effect of MMICCs on cell viability. The cytotoxic effect of MMICCs was evaluated by using the MTT cell proliferation assay at 24 and $72 \mathrm{~h}$ of cells incubation with MMICCs. Results were normalized to control cells and are shown as the mean \pm SEM of three independent experiments.

indicating that MMICCs were not cytotoxic for any of the cell types.

Effect of internalized MMICCs on cell morphology and adhesion

To verify whether internalization of MMICCs could affect cell morphology or focal contacts, actin cytoskeleton and vinculin were stained, respectively. The morphology and actin cytoskeleton structure of control MCF-10A and SKBR-3 cells was observed to be different. However, when cells with internalized 
MMICCs and cells without MMICCs were compared, no differences in the distribution of actin filaments and focal contacts were observed for any of the two cell lines (Fig. 5).
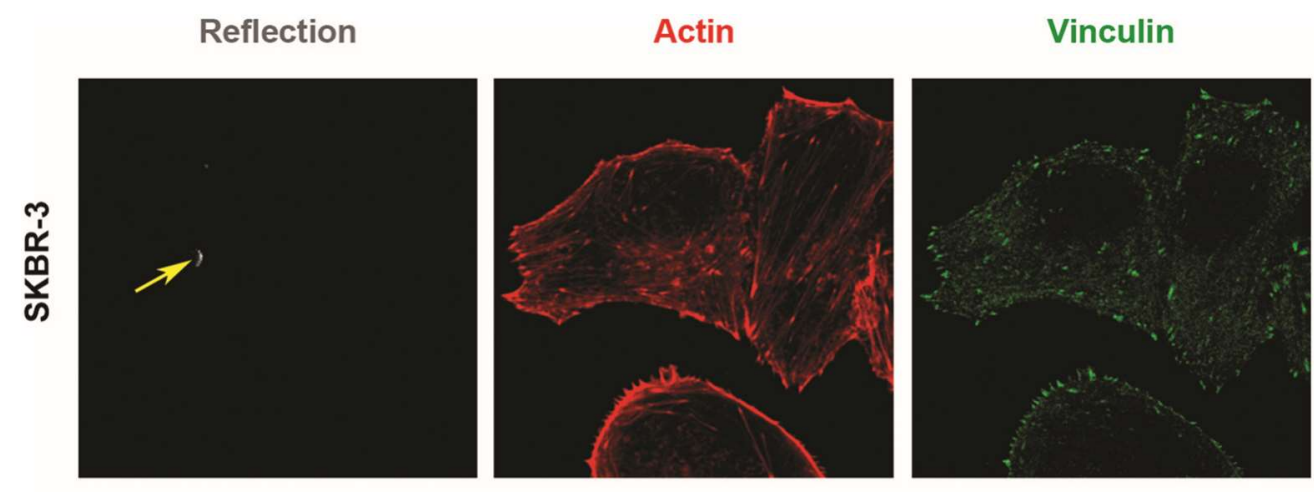

Overlay + Nuclei
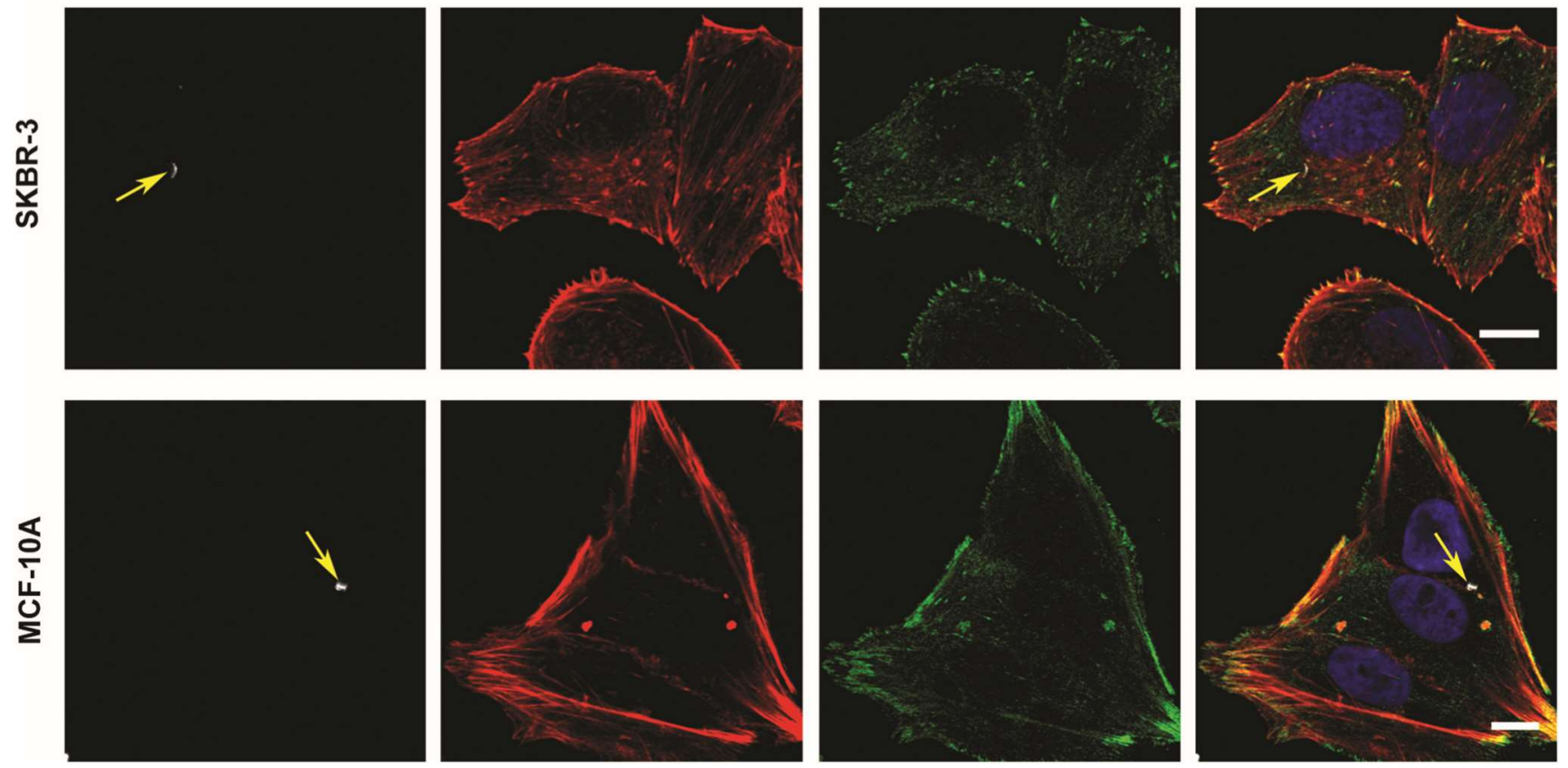

Fig. 5 Actin cytoskeleton organization and focal contacts in cells with or without MMICCs. Images show a single slice from a Z-stack, where the MMICCs are observed in gray, actin fibers are shown in red, focal contacts in green and nuclei in blue. Arrows indicate the internalized MMICC. Scale bar $=10 \mu \mathrm{m}$.

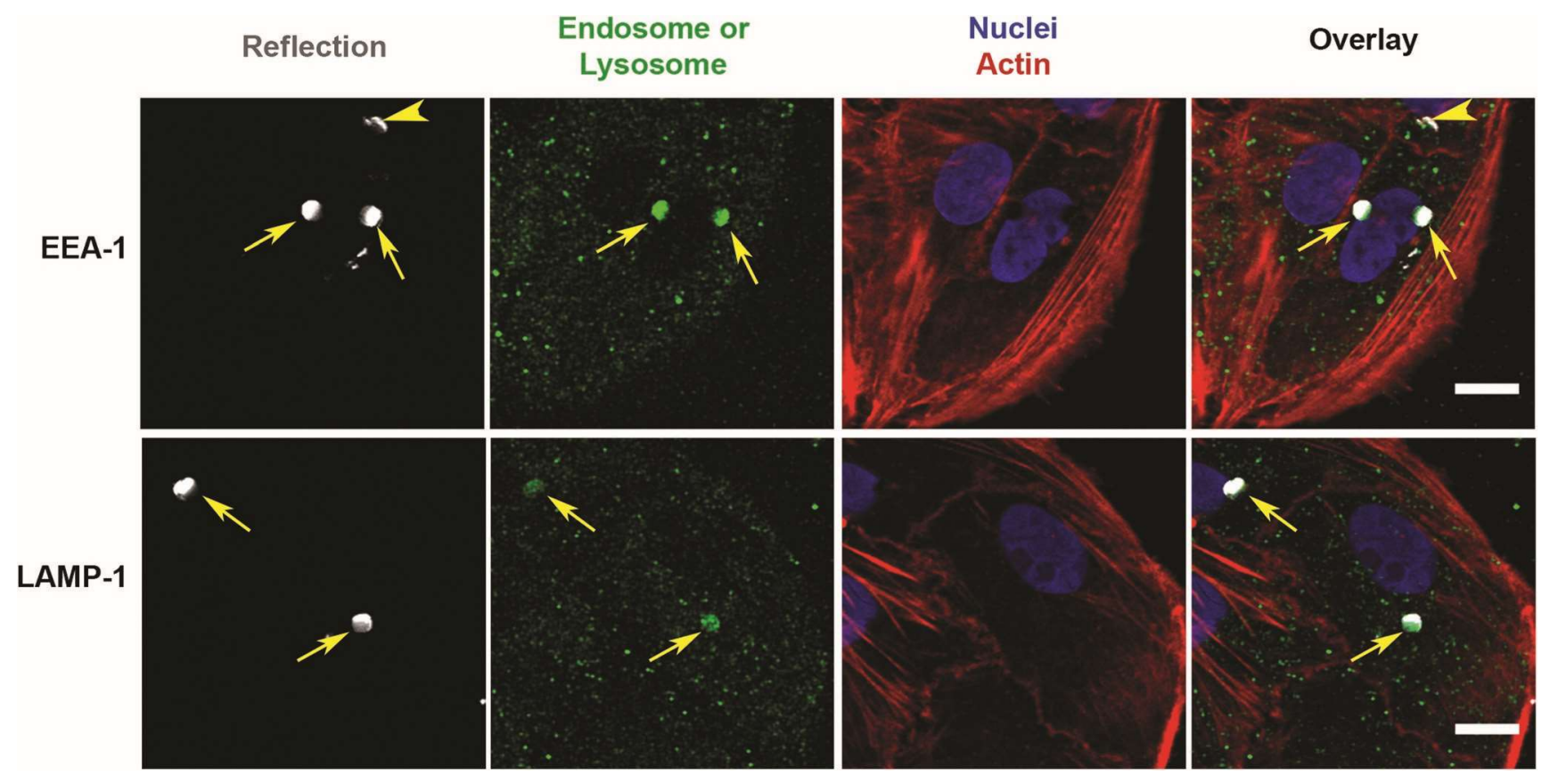


Fig. 6 CSLM analyses of MMICCs intracellular location in MCF-10A cells. In order to label the endosomal and lysosomal compartments, immunofluorescence detection of EEA-1 and LAMP-1 markers, respectively, was performed (green). Cell nuclei were stained with Hoechst 33258 (blue) and actin cytoskeleton was stained with Texas red ${ }^{\circledR}$ phalloidin (red). MMICCs were visualized by reflection (gray). Arrows indicate MMICCs located inside the endosomal or lysosomal compartments. Arrowhead indicates one chip that is not located inside the endosomal compartment. Scale bar $=10 \mu \mathrm{m}$.

\section{Intracellular location of MMICCs}

The evaluation of intracellular location of MMICCs was performed only in MCF-10A cells, as they showed a higher internalization rate than SKBR-3 cells. Immunolocalization of EEA-1 (endosomal compartment) and LAMP-1 (lysosomal compartment) proteins was carried out separately. After $24 \mathrm{~h}$ of incubation, MMICCs could be found in any of the two compartments (Fig. 6).

Induction of inflammatory cytokine secretion

To assess whether MMICCs could trigger an inflammatory response, we analyzed the release of four different human inflammatory cytokines, IL-1ß, IL-10, IL-6 and TNF- $\alpha$ by macrophages (Fig. 7). Macrophages incubated with LPS (positive control) showed a significant $(\mathrm{P}<0.05)$ increase of cytokine release when compared with the negative control. In contrast, macrophages incubated with MMICCs did not trigger an increased release of any of the studied inflammatory cytokines with respect to the negative control cells.

Transferrin receptor targeting and $\mathrm{pH}$ detection with multifunctional MMICCs

In order to render MMICCs to be multifunctional, they were functionalized with both pHrodo ${ }^{\mathrm{TM}}$ Red, SE and Tf-FITC (Fig. 8a and Scheme 1). The number of cells with internalized particles increased after the functionalization of MMICCs with Tf-FITC in both SKBR-3 and MCF-10A cell lines, but the extent of the increase was higher in the former than in the latter (Fig. 8b). In order to assess qualitatively the functionality of $\mathrm{pHrodo}^{\mathrm{TM}}$ Red, live cell imaging was performed (Fig. 8c-e). Depending on the orientation of the internalized MMICCs, Tf-FITC (green) or pHrodo $^{\mathrm{TM}}$ were detected. In the case of $\mathrm{pHRodo}^{\mathrm{TM}}$, red fluorescence indicated that MMICCs were located inside an acidic compartment, such as a lysosome or an endosome (Fig. 8c-e). 


\section{Discussion}

The fast advances in micro- and nanotechnologies in recent years have led to exciting outcomes regarding their application in the biomedical field. ${ }^{1,2,42}$ However, despite BioMEMs having excellent and controllable physicochemical properties for biomedical applications, a deeper understanding of their interaction with cells is required in order to improve their safety and effectiveness. ${ }^{28}$ In the present study, we assessed the biological interactions of $3 \mu \mathrm{m}$ pSi-Cr-Au MMICCs with tumorigenic SKBR-3 and non-tumorigenic MCF10A human breast epithelial cells. First, we characterized the size and composition of MMICCs. Results showed that the top-down microfabrication approach is very efficient in terms of producing highly homogeneous, size, shape, composition and monodispersed MMICCs, as it was expected. ${ }^{1}$ Although we previously reported that MMICCs could be internalized by macrophages, ${ }^{27}$ non-phagocytic cells have shown to internalize large particles with lower efficiency. ${ }^{20,43}$ In addition, we have

a)

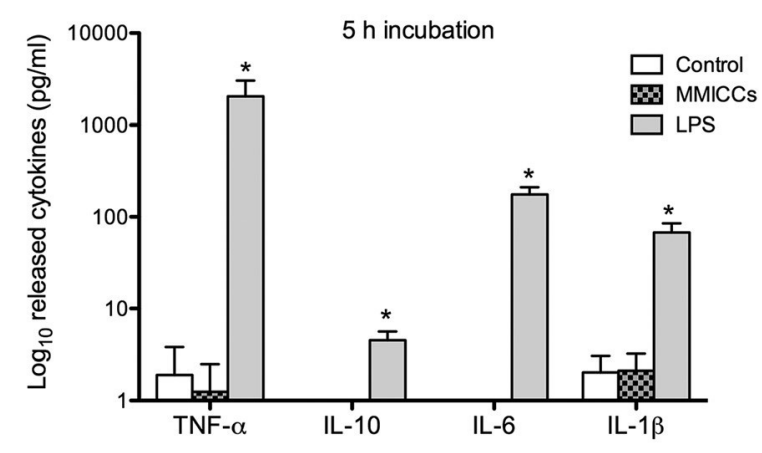

b)

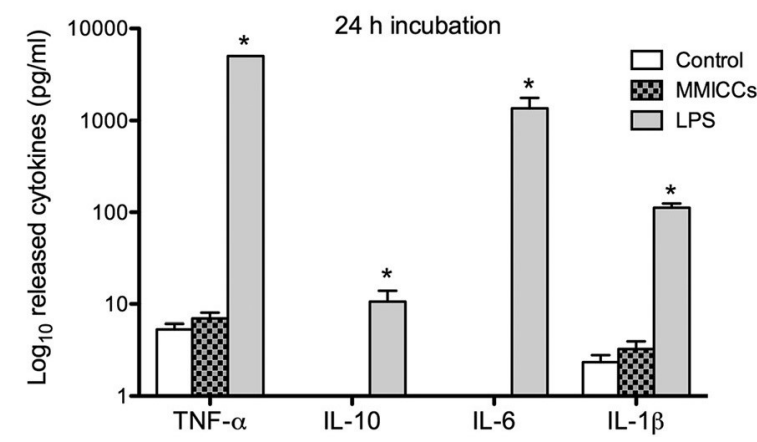

Fig. 7 Evaluation of MMICCs induction of human inflammatory cytokines secretion by macrophages, analyzed by flow cytometry. Quantification of human inflammatory cytokines was performed either $5 \mathrm{~h}$ (a) or $24 \mathrm{~h}$ (b) of MMICCs incubation with macrophages. Macrophages incubated in the absence of MMICCs (control) or in the presence of LPS acted as a negative and positive control, respectively. Results are shown as the mean \pm SEM of three independent experiments. Asterisks indicate significant differences $(\mathrm{p}<0.05)$ among groups (i.e. control, MMICCs or LPS). 
demonstrated that the uptake of micron-sized polystyrene particles is cell line dependent. ${ }^{44}$ Thus, we investigated whether the MMICCs could be taken up by two different types of nonphagocytic cell lines, one tumoral (SKBR-3) and another nontumoral (MCF-10A).

Although SEM analyses revealed that both cell lines could actively take up MMICCs, internalization analysis using CLSM showed that SKBR-3 cells had a lower capacity of internalizing MMICCs than MCF10A cells. This finding matches with previous studies, ${ }^{19,36,38,44}$ where the cell line was shown to play an important role when particle uptake is evaluated, highlighting that the target cell line must be considered as a critical point when designing new micro- and nanoengineered materials for intracellular applications. In our study, the elevated uptake of MMICCs by MCF-10A could be attributed to their negative surface charges when suspended in a serum free-culture medium, as this cell type has shown a clear preference for negative microparticle uptake. ${ }^{44}$

In addition to cellular uptake, the intracellular transport and fate of micro- and nanomaterials need to be well characterized. In this sense, micro- and nanoparticles have been shown to often remain trapped in endolysosomal compartments, which can be either desirable or not, depending on the purpose of the nanomaterial. ${ }^{45,46}$ In the present work, the study of the intracellular location of MMICCs using endosome and lysosome markers showed that, after $24 \mathrm{~h}$ of co-incubation, they could be found in any of these two compartments. These results are in agreement with previous studies where micro- and nanoparticles have been found to remain trapped in the endo-lysosomal compartments. ${ }^{47}$

Once the uptake and intracellular fate of MMICCs were evaluated, we studied their biocompatibility. In this regard, it is worth noting that in many cases micron-sized materials have been shown to render less cytotoxic effects when compared with their nano-sized counterparts, ${ }^{48,49}$ this being often correlated with a lower uptake. ${ }^{48}$ In spite of this, some authors have found significant cytotoxic effects for some types of microparticles, indicating that cytotoxicity not only depends on the size but also on material composition ${ }^{50}$ and surface properties. ${ }^{34}$ These findings suggest that cytotoxicity needs to be thoroughly evaluated in order to develop safe micro- and nanoengineered devices. For this reason, in the present study, we also assessed the viability, morphology and adhesion of cells incubated with MMICCs. First, we observed that the viability of both MCF-10A and SKBR-3 cells was not affected by the presence of MMICCs. Moreover, despite MMICCs being significantly more internalized in MCF-10A than in SKBR-3 cells, there were no significant differences in cell viability between these two cell lines. Second, the analyses of actin cytoskeleton and focal contacts showed no differences between cells with or without internalized MMICCs. Taken together, these results indicate that MMICCs do not affect cell viability regardless of the different uptake efficiency in both cell lines. 
Apart from cytotoxicity, another possible undesirable effect of MMICCs could be the induction of an inflammatory response. In this regard, it has been shown that macrophages can be used as a model, since they trigger the release of inflammatory cytokines as a response to the presence of certain materials, such as titanium debris, ${ }^{51,52}$ silicon ${ }^{53}$ and amorphous silica ${ }^{54}$ particles, as well as metal ions, such as $\mathrm{Au}, \mathrm{Pd}$ and Ni. ${ }^{55}$ Thus, we studied the inflammatory cytokines released by THP-1 derived macrophages after their incubation with MMICCs. We observed that the release of cytokines was not significantly affected by incubation with MMICCs, at either 5 or $24 \mathrm{~h}$, indicating that they do not trigger an immunogenic response in macrophages.

a)

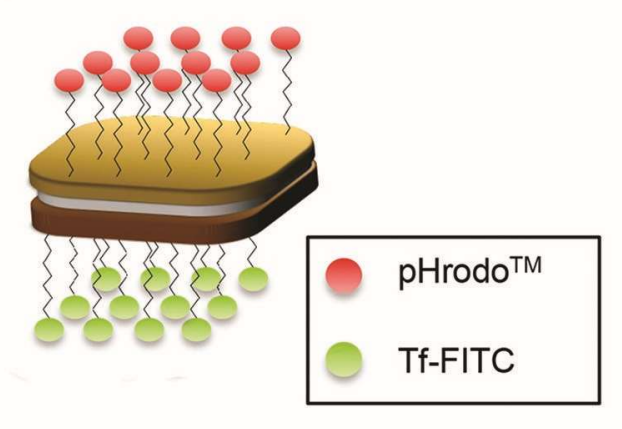

b)

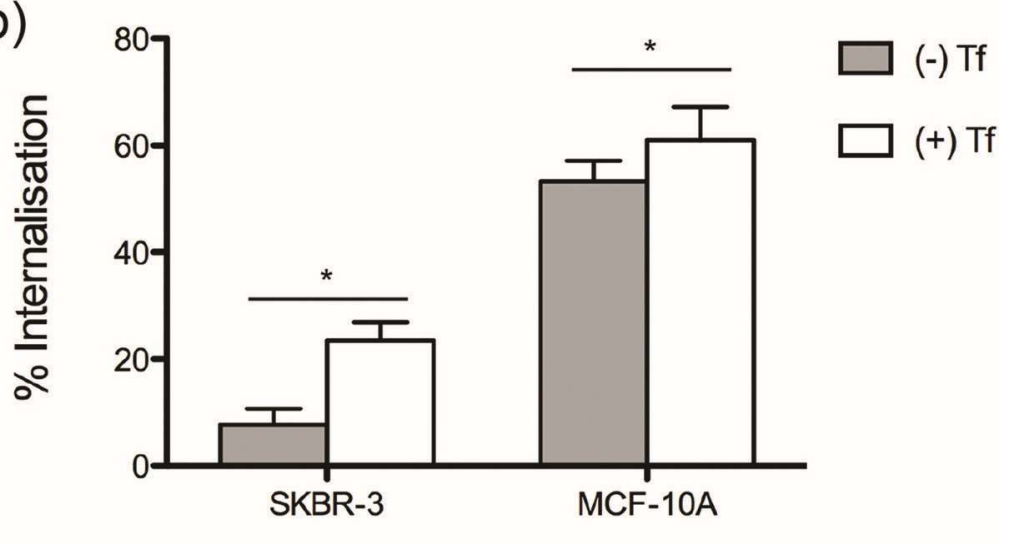

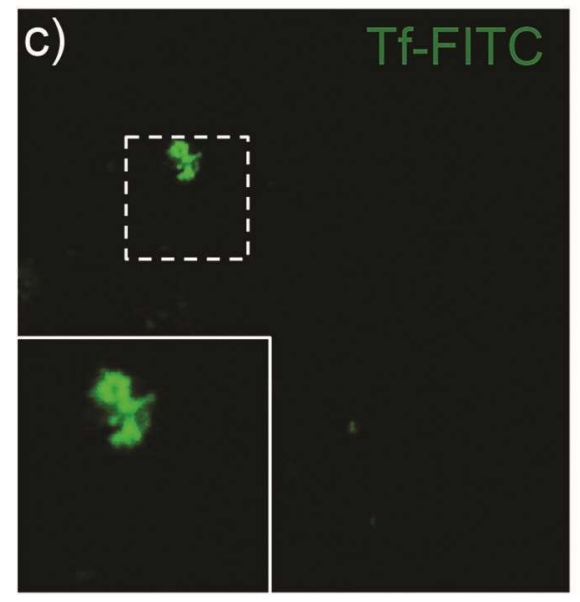
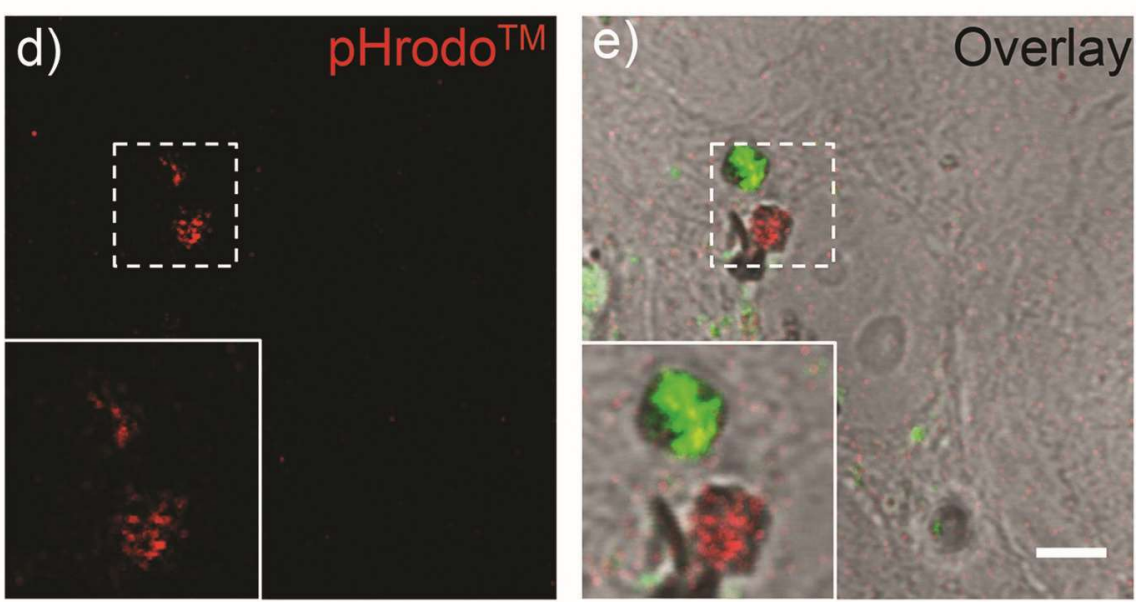
Fig. 8 Evaluation of bi-functionalized Tf-FITC/pHrodo ${ }^{\mathrm{TM}}$ Red MMICCs. (a) Schematic representation of surface modifications of MMICCs. (b) Percentage of cells with at least one internalized MMICC, either functionalized $(+\mathrm{Tf})$ or not $(-\mathrm{Tf})$. Results are shown as the mean $\pm \mathrm{SEM}$. Asterisk indicates significant differences between groups ( $\mathrm{p}<0.05$ ). (c-e) CSLM images showing a MCF-10A cell with internalized TfFITC/pHrodo ${ }^{\text {TM }}$ Red MMICCs. Scale bar $=10 \mu \mathrm{m}$. Insets show a magnification of the selected area.

In the last series of experiments of this work, MMICCs were bi-functionalized as a proof-of-concept for their potential use as multi-modal devices. Due to their multi-material nature, MMICCs offer unique properties such as the precise spatial control over surface-conjugated molecules. ${ }^{27}$ Since the transferrin receptor (TfR) has been shown to be overexpressed in a large number of malignant cancer cells, ${ }^{39-41,56}$ including SKBR-3 cells, ${ }^{57,58}$ we functionalized the poly-silicon side of MMICCs with Tf-FITC in order to target cancer cells. In addition, the Au side was functionalized with $\mathrm{pHrodo}^{\mathrm{TM}} \mathrm{Red}, \mathrm{SE}$, in order to detect intracellular $\mathrm{pH}$. Results showed that internalization of bi-functional MMICCs was significantly increased in both SKBR-3 and MCF-10A cell lines, when compared with non-functionalized MMICCs. However, this increase was higher in SKBR-3 (3-fold) than in MCF-10A cells (1.16-fold increase), probably due to their higher TfR expression level. In contrast, MCF-10A cells have shown to display low levels of TfR expression. ${ }^{40}$ Thus, these data indicate that MMICCs could be directed to a certain cell type by using specific targeting biomolecules. However, in this case MCF-10A cells showed a high capability for non-specific MMICC uptake, which would interfere with the targeting specificity. On the other hand, the red fluorescence of pHrodo $^{\mathrm{TM}}$ Red could be visualized, indicating that MMICCs were located inside acidic compartments, which is in agreement with our data about the intracellular location studies using EEA-1 and LAMP-1 markers.

\section{Experimental}

Fabrication and characterization of MMICCs

MMICCs were fabricated through photolithographic techniques combined with silicon microelectronic and micromachining technologies, as previously described. ${ }^{27}$

Briefly, a $1 \mu \mathrm{m}$-thick silicon oxide sacrificial layer was deposited in a $100 \mathrm{~mm} \varnothing \mathrm{p}$-type silicon wafer, followed by a $400 \mathrm{~nm}$ thick polysilicon layer deposition. Then, a photoresist inverse pattern was created through photolithography, which was followed by the deposition of a $30 \mathrm{~nm}$ thick chromium layer as an adherent layer. Next, a $100 \mathrm{~nm}$ thick gold layer was deposited, defining the second device layer. The chips were defined by the dry etching of polysilicon for $25 \mathrm{~s}$, where the gold layer was used as a mask. To release 
the chips, a sacrificial etching of silicon oxide sacrificial layers was performed. Finally, chips were collected and stored.

Once collected, MMICCs were stored at room temperature (RT) until used in further experiments. In order to characterize the size, shape and material composition, MMICCs were evaluated under a scanning electron microscope (SEM) (Carl Zeiss Merlin-Microscope GmbH) equipped with an Energy DispersiveX-ray spectroscope (EDX). In addition, the electrophoretic mobility ( $\zeta$-potential) of MMICCs and singlematerial (gold or polysilicon) chips suspended in serum-free culture medium were obtained by using a Zetasizer Nano ZS (Malvern

Instruments).

a b<smiles>C1CCCCC1</smiles>
d e

f

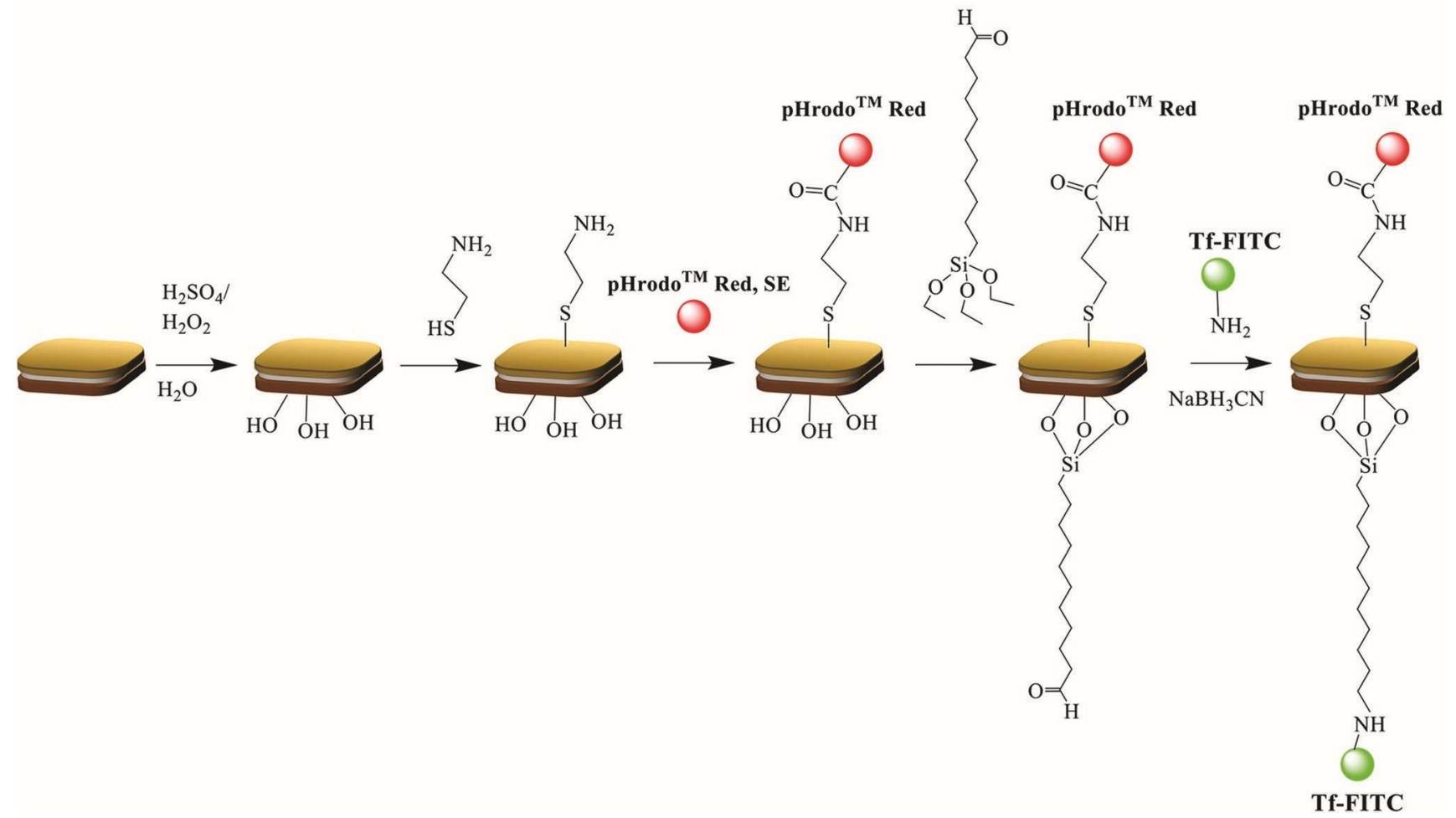

Scheme 1 Stepwise functionalization of multi-material polysilicon-Cr-Au intracellular chips (MMICCs) with Tf/FITC and pHrodo ${ }^{\mathrm{TM}}$ Red, succinimidyl ester (pHrodo ${ }^{\mathrm{TM}}$ Red, SE). (a) MMICCs, (b) polysilicon activation, (c) cysteamine SAM formation on gold, (d) pHrodo® immobilization (e) TESUD SAM formation on polysilicon and (f) Tf-FITC immobilization.

Cell culture 
Cell uptake and cytotoxicity studies were conducted using two different non-phagocytic human mammary epithelial cell lines. One of these cell lines was non-tumorigenic (MCF-10A), whereas the other had a tumoral origin (SKBR-3). MCF-10A cells were cultured in DMEM/F12 (Gibco) supplemented with 5\%

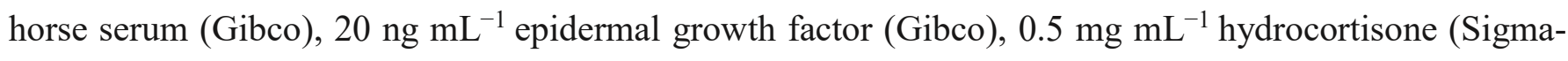
Aldrich, St Louis, MO, USA), $100 \mathrm{ng} \mathrm{mL}^{-1}$ cholera toxin (Sigma-Aldrich) and $10 \mu \mathrm{g} \mathrm{m}^{-1}$ insulin (Gibco). Adenocarcinoma SKBR-3 cells were cultured in McCoy's 5A modified medium (Gibco) supplemented with $10 \%$ fetal bovine serum (FBS, Gibco).

Analysis of inflammatory cytokines secretion was conducted using macrophages derived from the human leukemia monocyte THP-1 cell line. THP-1 cells were cultured in RPMI 1640 medium (Gibco) supplemented with 20\% FBS (Gibco). To differentiate THP-1 monocytes into macrophages, cells were seeded in 96-multiwell plates at a density of 60000 cells per well and treated with $0.16 \mu \mathrm{M}$ phorbol-12myristate-13-acetate (Sigma) for $72 \mathrm{~h}$.

All cell lines were purchased from ATCC and maintained at $37{ }^{\circ} \mathrm{C}$ and $5 \% \mathrm{CO}_{2}$ (standard conditions). The culture medium was refreshed every $72 \mathrm{~h}$.

Analysis of MMICC uptake by scanning electron and confocal microscopy

Evaluation of MMICC uptake was first carried out by SEM. Cells were seeded in $3.5 \mathrm{~mm}$ diameter glass bottom dishes (MatTEK) at a density of $1.5 \times 10^{5}$ cells per dish. At $24 \mathrm{~h}$, MMICCs were added to the culture medium at a particle : cell ratio of $5: 1$. Cells were incubated with MMICCs for either 4 or $24 \mathrm{~h}$. Then, cells were fixed in $2.5 \%$ glutaraldehyde in cacodylate buffer, dehydrated in an ethanol series, dried with hexamethyl disilazane (Electron Microscopy Sciences) for 15 min and observed under a SEM (Carl Zeiss Merlin).

To further study and quantify MMICC uptake, cells were seeded on glass coverslips in 24-well plates, at a density of 50000 cells per well. After 24 h, MMICCs were added to the cell culture at a particle : cell ratio of $5: 1$. At $24 \mathrm{~h}$ of incubation, cells were fixed with $4 \%$ paraformaldehyde (PFA) in phosphate buffered saline (PBS) for $20 \mathrm{~min}$ and blocked for $40 \mathrm{~min}$ with 1\% bovine serum albumin (BSA, Sigma-Aldrich) in PBS. Cells were subsequently stained with Texas Red®conjugated phalloidin (TR-Phal; $10 \mu \mathrm{g} \mathrm{mL}{ }^{-1}$; Life Technologies) and counterstained with Hoechst $33258\left(1 \mu \mathrm{g} \mathrm{mL}{ }^{-1}\right.$; Sigma-Aldrich) to visualize the cell cortex and the nucleus, respectively. Then, the samples were washed thrice in PBS for 5 min, air dried and mounted using Fluoroprep solution (Biomerieux). Mounted samples were observed under a confocal laser scanning microscope (CLSM, Olympus XT7) using a 60× oil immersion objective.

For the detection of TR-Phal, excitation and emission wavelengths of $559 \mathrm{~nm}$ and $590 \mathrm{~nm}$, respectively, were used. Excitation and emission wavelengths for Hoechst 33258 were $405 \mathrm{~nm}$ and $461 \mathrm{~nm}$, respectively. 
MMICCs were visualized by detecting the reflected light using an excitation wavelength of $488 \mathrm{~nm}$. ZStacks were obtained by $\mathrm{x}-\mathrm{y}-\mathrm{z}$ sequential acquisition and orthogonal projections of the stacks were analyzed to determine the location of MMICCs within the cell. For image analysis, the FV10-ASW Application Software (Ver. 01.07c; Olympus) was used. For each experiment, 200 cells per cell type were analyzed and three independent experiments were performed.

\section{Cytotoxicity}

Cells were seeded in 24-well dishes at a density of 50000 cells per well and were allowed to grow for 24 h. Then, MMICCs were added to the cell culture at a particle : cell ratio of $5: 1$. After 24 and $72 \mathrm{~h}$ of incubation, the viability of cells was evaluated using the Vybrant MTT Cell Proliferation Assay Kit (Molecular Probes), according to the manufacturer's instructions. Briefly, the culture medium was replaced by $200 \mu \mathrm{L}$ of fresh culture medium containing $20 \mu \mathrm{L}$ of MTT stock solution (12 mM). After incubation at $37{ }^{\circ} \mathrm{C}$ and $5 \% \mathrm{CO}_{2}$ for $2 \mathrm{~h}$, the medium was removed and the formazan crystals were dissolved by adding $200 \mu \mathrm{L}$ of dimethyl sulfoxide (Sigma-Aldrich). Cells were incubated for 10 min at $37{ }^{\circ} \mathrm{C}$ and $5 \% \mathrm{CO}_{2}$ for the complete solubilization of formazan crystals. Then, the measurement of absorbance was conducted at $570 \mathrm{~nm}$ using a Victor 3 Multilabel counter (PerkinElmer). For each treatment, viability was calculated as the absorbance of cells exposed to MMICCs divided by the absorbance of non-exposed, control cells. Three independent experiments were performed.

Immunodetection of actin cytoskeleton and focal adhesions

Cells were seeded on glass coverslips in 4-well dishes at a density of 50000 cells per well. After $24 \mathrm{~h}$, MMICCs at a particle : cell ratio of $5: 1$ were added to the cell culture. At 4 and $24 \mathrm{~h}$ of co-incubation, cells were fixed with 4\% PFA in PBS for 20 min, subsequently permeabilized with $0.1 \%$ Triton X-100 (Sigma) in PBS for $15 \mathrm{~min}$, and blocked with 5\% BSA in PBS for $40 \mathrm{~min}$. To visualize focal adhesions, the samples were incubated with a mouse anti-vinculin antibody (Chemicon) for $60 \mathrm{~min}$ at RT. Next, the samples were rinsed in PBS and incubated with a mixture of Alexa Fluor ${ }^{\circledR 594-c o n j u g a t e d ~ P h a l l o i d i n ~}$ (Invitrogen), Alexa Fluor ${ }^{2} 488$ goat anti-mouse IgG secondary antibody (Invitrogen) and Hoechst 33258 (Sigma-Aldrich) at RT for $1 \mathrm{~h}$. Finally, the samples were washed thrice in PBS for $5 \mathrm{~min}$, air dried, and mounted using Fluoroprep solution (Biomerieux). The samples were imaged under a CLSM.

Immunodetection of endosomes and lysosomes

Cells were seeded on glass coverslips in 4-well dishes, at a density of 50000 cells per well. After $24 \mathrm{~h}$, MMICCs at a 5:1 particle : cell ratio were added to the culture, in serum free medium. At $24 \mathrm{~h}$ of 
incubation, cells were fixed with 4\% PFA in PBS for 20 min, permeabilized with $0.1 \%$ Triton X-100 in PBS for 15 min and blocked for 40 min with 5\% BSA in PBS. Endosomes and lysosomes were stained by incubating cells with a mouse anti-EEA-1 monoclonal antibody or a mouse anti-LAMP-1 polyclonal antibody (both from BD Biosciences), respectively. Following this, cells were washed thrice with PBS and incubated with an Alexa Fluor ${ }^{\circledR}$ 488-conjugated chicken anti-mouse IgG antibody (Life technologies). At the same time, cytocortex was labelled with TR-Phal at RT for $1 \mathrm{~h}$. Cells were observed under a CLSM in order to determine the intracellular location of MMICCs.

Inflammatory cytokines secretion analysis

To study the possible induction of an inflammatory response by MMICCs, the human inflammatory cytokines (i.e. TNF $\alpha$, IL1 $\beta$, IL6, IL10) profile released by macrophages was analyzed using a flow cytometry bead array (CBA, Becton-Dickinson). Briefly, cells were seeded and differentiated as detailed in the cell culture section. After $72 \mathrm{~h}$ of differentiation, cells were exposed to MMICCs at a particle : cell ratio of $2: 1$. As a positive control, lipopolysaccharide (LPS; Sigma-Aldrich) was added to the culture medium at a final concentration of $1 \mu \mathrm{g} \mathrm{mL}^{-1}$. As a negative control, macrophages were cultured in the absence of both MMICC and LPS. After 5 or $24 \mathrm{~h}$ of incubation, the supernatants of the cell cultures were collected and analyzed using a Becton-Dickinson FACSCanto II flow cytometer (BD Biosciences) equipped with BD Biosciences FACSDiva ${ }^{\mathrm{TM}}$ software. Three independent experiments were carried out.

\section{Functionalization of MMICCs with Tf-FITC and $\mathrm{pHrodo}^{\mathrm{TM}}$}

Red, succinimidyl ester (pHrodo ${ }^{\mathrm{TM}}$ Red, SE)

MMICCs were orthogonally functionalized following a modification of the protocol previously described. ${ }^{27}$ Briefly, polysilicon was oxidized through piranha solution $\mathrm{H}_{2} \mathrm{SO}_{4}: \mathrm{H}_{2} \mathrm{O}_{2}(7: 3)$ for $1 \mathrm{~h}$. Then, MMICCs were washed thrice in MilliQ water by centrifugation (13 $400 \mathrm{rpm}, 10 \mathrm{~min}$ ). Next, MMICCs were incubated with an ethanol solution of $25 \mathrm{mM}$ cysteamine for $3 \mathrm{~h}$ and washed thrice with ethanol by centrifugation (13 $400 \mathrm{rpm}, 10 \mathrm{~min})$. Then, a dimethyl sulfoxide (DMSO) solution of $\mathrm{pHrodo}^{\mathrm{TM}} \mathrm{Red}, \mathrm{SE}(17 \mu \mathrm{M})$ (Invitrogen) was added to the MMICCs suspension and the mixture was maintained at RT overnight. Next, MMICCs were washed by centrifugation as aforementioned using DMSO, and a mixture of $135 \mathrm{mM}$ TESUD in ethanol and acetic buffer ( $\mathrm{pH}$ 5.2) was added to the MMICCs suspension and incubated for $3 \mathrm{~h}$ at RT. MMICCs were then washed by centrifugation using ethanol. Following this, a PBS solution containing TfFITC $\left(50 \mu \mathrm{g} \mathrm{mL}^{-1}\right)$ (Invitrogen) and $5 \mathrm{mM}$ sodium cyanoborohydride was added to the MMICCs 
suspension. The mixture was kept at $4{ }^{\circ} \mathrm{C}$ overnight. Finally, bi-functionalized MMICCs were washed by centrifugation using PBS and kept in sterile PBS until their use. The protocol is summarized in Scheme 1. Evaluation of dual-functionalized MMICC uptake

The uptake of Tf-FITC and pHrodo ${ }^{\text {TM }}$ Red functionalized MMICCs by both cell lines was analyzed under CSLM, as described previously. For each cell line, 200 cells were evaluated and three independent experiments were performed. Besides, in order to qualitatively evaluate the functionality of $\mathrm{pHrodo}^{\mathrm{TM}}$ conjugated to the MMICCs, life cell imaging was performed under CSLM. For each experiment, 15 cells per cell type were analyzed and three independent experiments were performed.

Statistical analyses

All statistical analyses were conducted using a statistical package (IBM® SPSS ${ }^{\circledR}$ for Windows, Ver. 21.0; IBM Corp.). In all cases, data were first tested for normality (Shapiro-Wilk test) and homogeneity of variances (Levene test) and, when required, transformed through arcsine square-root transformation.

On the one hand, the cytotoxic effects of exposing SKBR-3 and MCF-10A cells to MMICCs were evaluated through a repeated measures analysis of variance (ANOVA), where the MTT assay outcome was the variable, the treatment (presence or absence of MMICCs) was the between-subjects factor and the incubation time ( 24 or $72 \mathrm{~h}$ ) was the within-subjects factor.

On the other hand, percentages of MMICCs taken up by SKBR-3 and MCF-10A cells were compared through a t-test for independent samples.

Finally, the effects of co-incubating MMICCs with macrophages derived from THP-1 monocytes on the cytokine profile were evaluated with repeated measures ANOVA, followed by a Sidak post-hoc test. In each case, the individual cytokine was the variable, the treatment (with MMICCs, negative control and positive control, with LPS) was the between-subjects factor and the incubation time (5 or $24 \mathrm{~h}$ ) was the within-subjects factor.

In all cases, the minimal significance level was set at $\mathrm{P} \leq 0.05$.

Data are shown as mean \pm standard error of the mean (SEM).

\section{Conclusions}

In summary, our results show that multi-material devices have a promising potential for their use in intracellular applications and theranostics due to their excellent biocompatible and nonimmunogenic properties, as well as for the development of different functions such as targeting and sensing. Moreover, our results highlight the importance of a prior characterization of their interactions with biological systems, 
not only regarding their target cells but also the cells from the neighboring tissues, in order to develop an efficient and safe micron-sized platform for biomedical purposes.

Acknowledgements

This work was supported by the EU-ERDF (FEDER), the Spanish Government (TEC2011-29140-C03; TEC2014-51940C2), and the Generalitat de Catalunya (2014SGR-524) grants.

EA thanks the Generalitat de Catalunya for a pre-doctoral grant (FI). The authors wish to thank the Servei de Microscòpia at the Universitat Autònoma de Barcelona.

\section{References}

1 M. Caldorera-Moore and N. A. Peppas, Adv. Drug Delivery Rev., 2009, 61, 1391-1401.

2 C. T. Lim, J. Han, J. Guck and H. Espinosa, Med. Biol. Eng. Comput., 2010, 48, 941-943.

3 M. C. Roco, Curr. Opin. Biotechnol., 2003, 14, 337-346. 4 R. A. Siegel, E. E. Nuxoll, M. A. Hillmyer and B. Ziaie, IEEE Eng. Med. Biol. Soc., 2009, 232-235.

5 E. Nuxoll, Adv. Drug Delivery Rev., 2013, 65, 1611-1625. 6 R. S. Shawgo, A. C. Richards Grayson, Y. Li and M. J. Cima, Curr. Opin. Solid State Mater. Sci., 2002, 6, 329-334. 7 S. L. Tao and T. A. Desai, Adv. Drug Delivery Rev., 2003, 55, 315-328.

8 J. Z. Hilt and N. A. Peppas, Int. J. Pharm., 2005, 306, 15-23. 9 S. Sant, S. L. Tao, O. Z. Fisher, Q. Xu, N. A. Peppas and

A. Khademhosseini, Adv. Drug Delivery Rev., 2012, 64, 496-507.

10 J. T. Santini, M. J. Cima and R. Langer, Nature, 1999, 397, 335-338.

11 J. T. Santini, A. C. Richards, R. Scheidt, M. J. Cima and R. Langer, Angew. Chem., Int. Ed., 2000, 39, 2396-2407.

12 M. Staples, Wiley Interdiscip. Rev.: Nanomed. Nanobiotechnol., 2010, 2, 400-417.

13 R. Bashir, Adv. Drug Delivery Rev., 2004, 56, 1565-1586.

14 E. Fernandez-Rosas, R. Gomez, E. Ibanez, L. Barrios, M. Duch, J. Esteve, C. Nogues and J. A. Plaza, Small, 2009, 5, 2433-2439.

15 E. Fernandez-Rosas, R. Gomez, E. Ibanez, L. Barrios, M. Duch, J. Esteve, J. A. Plaza and C. Nogues, Biomed. Microdevices, 2010, 12, 371-379.

16 R. Gómez-Martínez, P. Vázquez, M. Duch, A. Muriano, 
D. Pinacho, N. Sanvicens, F. Sánchez-Baeza, P. Boya, E. J. de la Rosa, J. Esteve, T. Suárez and J. A. Plaza, Small, 2010, 6, 499-502.

17 R. Gomez-Martinez, A. M. Hernandez-Pinto, M. Duch, P. Vazquez, K. Zinoviev, E. J. de la Rosa, J. Esteve, T. Suarez and J. A. Plaza, Nat. Nanotechnol., 2013, 8, 517-521. 18 S. E. A. Gratton, P. A. Ropp, P. D. Pohlhaus, J. C. Luft, V. J. Madden, M. E. Napier and J. M. DeSimone, Proc. Natl. Acad. Sci. U. S. A., 2008, 105, 11613-11618. 19 W. Zauner, N. A. Farrow and A. M. Haines, J. Controlled Release, 2001, 71, 39-51.

20 J. Rejman, V. Oberle, I. S. Zuhorn and D. Hoekstra,

Biochem. J., 2004, 377, 159-169.

21 J. A. Champion, A. Walker and S. Mitragotri, Pharm. Res., 2008, 25, 1815-1821.

22 S. Barua, J.-W. Yoo, P. Kolhar, A. Wakankar, Y. R. Gokarn and S. Mitragotri, Proc. Natl. Acad. Sci. U. S. A., 2013, 110, 3270-3275.

23 Y. Geng, P. Dalhaimer, S. Cai, R. Tsai, M. Tewari, T. Minko and D. E. Discher, Nat. Nanotechnol., 2007, 2, 249-255.

24 S. S. Kelkar and T. M. Reineke, Bioconjugate Chem., 2011, 22, 1879-1903.

25 M. Rahman, M. Z. Ahmad, I. Kazmi, S. Akhter, M. Afzal, G. Gupta, F. Jalees Ahmed and F. Anwar, Expert Opin. Drug Delivery, 2012, 9, 367-381.

26 P. Debbage, Curr. Pharm. Des., 2009, 15, 153-172.

27 S. Durán, M. Duch, T. Patiño, A. Torres, O. Penon,

R. Gómez-Martínez, L. Barrios, J. Esteve, C. Nogués, L. Pérez-García and J. A. Plaza, Sens. Actuators, B, 2015, 209, 212-224.

28 W. J. Stark, Angew. Chem., Int. Ed., 2011, 50, 1242-1258.

29 S. Tomic, J. Ethokic, S. Vasilijic, N. Ogrinc, R. Rudolf,

P. Pelicon, D. Vucevic, P. Milosavljevic, S. Jankovic, I. Anzel, J. Rajkovic, M. S. Rupnik, B. Friedrich and M. Colic, PLoS One, 2014, 9, e96584.

30 F. Blank, P. A. Stumbles, E. Seydoux, P. G. Holt, A. Fink, B. Rothen-Rutishauser, D. H. Strickland and C. von

Garnier, Am. J. Respir. Cell Mol. Biol., 2013, 49, 67-77. 31 B. D. Chithrani, A. A. Ghazani and W. C. W. Chan, Nano

Lett., 2006, 6, 662-668.

32 N. M. Schaeublin, L. K. Braydich-Stolle, E. I. Maurer, 
K. Park, R. I. MacCuspie, A. R. M. N. Afrooz, R. A. Vaia, N. B. Saleh and S. M. Hussain, Langmuir, $2012,28,3248-3258$.

33 Y. Qiu, Y. Liu, L. Wang, L. Xu, R. Bai, Y. Ji, X. Wu, Y. Zhao, Y. Li and C. Chen, Biomaterials, 2010, 31, 7606-7619. 34 E. Frohlich, Int. J. Nanomed., 2012, 7, 5577-5591.

35 T. Patiño, C. Nogués, E. Ibáñez and L.Barrios,

Int. J. Nanomed., 2012, 7, 5671-5682. 36 K. Saha, S. T. Kim, B. Yan, O. R. Miranda, F. S. Alfonso, D. Shlosman and V. M. Rotello, Small, 2013, 9, 300-305.

37 D. A. Kuhn, D. Vanhecke, B. Michen, F. Blank, P. Gehr,
A. Petri-Fink
and
B.
Rothen-Rutishauser, Beilstein

J. Nanotechnol., 2014, 5, 1625-1636.

38 E. C. Wang, R. Sinnott, M. E. Werner, M. Sethi,

A. W. Whitehurst and A. Z. Wang, Nanomedicine, 2014, 10, 321-328.

39 R. Kolhatkar, A. Lote and H. Khambati, Curr. Drug Discovery Technol., 2011, 8, 197-206.

40 D. Hogemann-Savellano, E. Bos, C. Blondet, F. Sato, T. Abe, L. Josephson, R. Weissleder, J. Gaudet, D. Sgroi, P. J. Peters and J. P. Basilion, Neoplasia, 2003, 5, 495-506.

41 P. G. Cavanaugh, L. Jia, Y. Zou and G. L. Nicolson, Breast Cancer Res. Treat., 1999, 56, $203-217$.

42 T. James, M. S. Mannoor and D. V. Ivanov, Sensors, 2008, 8, 6077-6107.

43 D. L. J. Thorek and A. Tsourkas, Biomaterials, 2008, 29, 35833590.

53 J. Choi, Q. Zhang, V. Reipa, N. S. Wang, M. E. Stratmeyer, V. M. Hitchins and P. L. Goering, J. Appl. Toxicol., 2009, 29, 52-60.

44 T. Patiño, J. Soriano, L. Barrios, E. Ibáñez and C. Nogués, Sci. Rep., 2015, 5, 11371.

54 T. Kusaka, M. Nakayama, K. Nakamura, M. Ishimiya, E. Furusawa and K. Ogasawara, PLoS One, 2014, 9, e92634.

45 L. M. Bareford and P. W. Swaan, Adv. Drug Delivery Rev., 2007, $59,748-758$.

55 J. C. Wataha, J. B. Lewis, K. R. Volkmann, P. E. Lockwood, R. L. W. Messer and S. Bouillaguet, J. Biomed. Mater. Res., Part B, 2004, 69, 11-17.

46 H. K. Shete, R. H. Prabhu and V. B. Patravale, J. Nanosci. Nanotechnol., 2014, 14, 460-474.

47 T.-G. Iversen, T. Skotland and K. Sandvig, Nano Today, 2011, 6, 176-185.

48 Q. He, Z. Zhang, Y. Gao, J. Shi and Y. Li, Small, 2009, 5, 27222729.

49 S. Nair, A. Sasidharan, V. V. Divya Rani, D. Menon, S. Nair, K. Manzoor and S. Raina, J. Mater. Sci. Mater. Med., 2009, 20, 235241.

50 H. L. Karlsson, J. Gustafsson, P. Cronholm and L. Möller, Toxicol. Lett., 2009, 188, 112-118.

51 Y. Nakashima, D. H. Sun, M. C. Trindade, W. J. Maloney, S. B. Goodman, D. J. Schurman and R. L. Smith, J. Bone Jt. Surg., Am. Vol., 1999, 81, 603-615.

52 G. Valles, P. Gonzalez-Melendi, J. L. Gonzalez-Carrasco, L. Saldana, E. Sanchez-Sabate, L. Munuera and N. Vilaboa, Biomaterials, 2006, 27, 5199-5211.

56 T. R. Daniels, T. Delgado, G. Helguera and M. L. Penichet, Clin. Immunol., 2006, 121, 159-176. 57 M. Kawamoto, T. Horibe, M. Kohno and K. Kawakami, BMC Cancer, 2011, 11, 359.

58 Q. Zheng, Y.-L. Xiong, Z.-J. Su, Q.-H. Zhang, X.-Y. Dai, L.-Y. Li, X. Xiao and Y.-D. Huang, Protein Expression Purif., 2013, 89, $181-188$. 